\title{
VIJF VOORWERPEN UIT HET BEZIT VAN \\ A.E. VAN BRAAM HOUCKGEEST
}

ZEER RECENT HEEFT het Rijksmuseum Amsterdam een kleine groep objecten gekocht uit de verzameling van Andreas Everardus van Braam Houckgeest (1739-1801). Het zijn een achter-glas-schildering met het portret van Catharina Geertruida van Reede van Oudtshoorn, de eerste vrouw van Van Braam (afb. 1); een paar armstoelen met het monogram VBH; een spiegelstandaard met de initialen ECSVB, voor Everarda Catharina Sophia van Braam Houckgeest, de enige volwassen dochter van Van Braam; een ivoren en deels beschilderde waaier; en een paar achter-glas-schilderingen naar voorbeelden van Europese meesters.

VAN BRAAM HouckgeEst is zonder twijfel een van de belangrijkste figuren uit de geschiedenis van de Nederlands-Chinese relaties. Als hoge VOCdienaar in Kanton nam hij in 1795 het initiatief voor de Nederlandse ambassade naar het Chinese hof in Peking, een ambassade waaraan hij zelf als vice-ambassadeur deelnam. Van Braam heeft de reis uitvoerig gedocumenteerd in een reisverslag (gepubliceerd in Philadelphia 1797-1798) en in eigen schetsen; bovendien greep hij de reis aan om een zo uitgebreid mogelijke collectie afbeeldingen en voorwerpen in China bijeen te brengen. Vanwege de ongewisse situatie in Europa vestigde hij zich in 1795 met zijn omvangrijke Chinese collectie in de VS, nabij Philadelphia. Op dat moment was het de grootste en meest veelzijdige China-collectie in de Westerse wereld. Van Braams huis bood plaats aan de 'atlas' met de duizenden albumbladen, en was verder geheel ingericht met meubelen, gebruiks- en kunstvoorwerpen die vervaardigd waren in de ateliers in Kanton.

Door financiële tegenvallers moest Van Braam al in 1799 vrijwel de gehele collectie verkopen. De voorwerpen zijn daardoor over de wereld verspreid geraakt en afgezien van enige kaarten in het Nationaal Archief was niets van deze belangrijke collectie in Nederlandse openbare collecties aanwezig. De voorwerpen die nu zijn aangekocht, werden niet verkocht in 1799, maar zijn via de oudste dochter van Van Braam vererfd en zonder onderbreking in het bezit van de familie gebleven.

\footnotetext{
Afbeelding 1 (pagina 31)

Spiegel, gedeeltelijk achter-glas beschilderd, China, 1790-1795, 55,4 ×45,2 cm.

'Hoop' draagt het medaillon met het portret van mevrouw Van Braam Houckgeest. De lelietakken en het anker zijn bekende attributen van de Hoop; de wierookbrander is minder gebruikelijk en kan naar Azië verwijzen. Linksonder is in grisaille een in steen gehakt reliêf gesuggereerd met een afscheidsscène: een vrouw wordt ondersteund en wuift wenend een schip uit. 'Vota sequuntur Euntum' (onze goede wensen vergezellen hem) staat eronder. Rechtsonder zijn de wapenschilden van Van Braam en zijn vrouw geschilderd. 


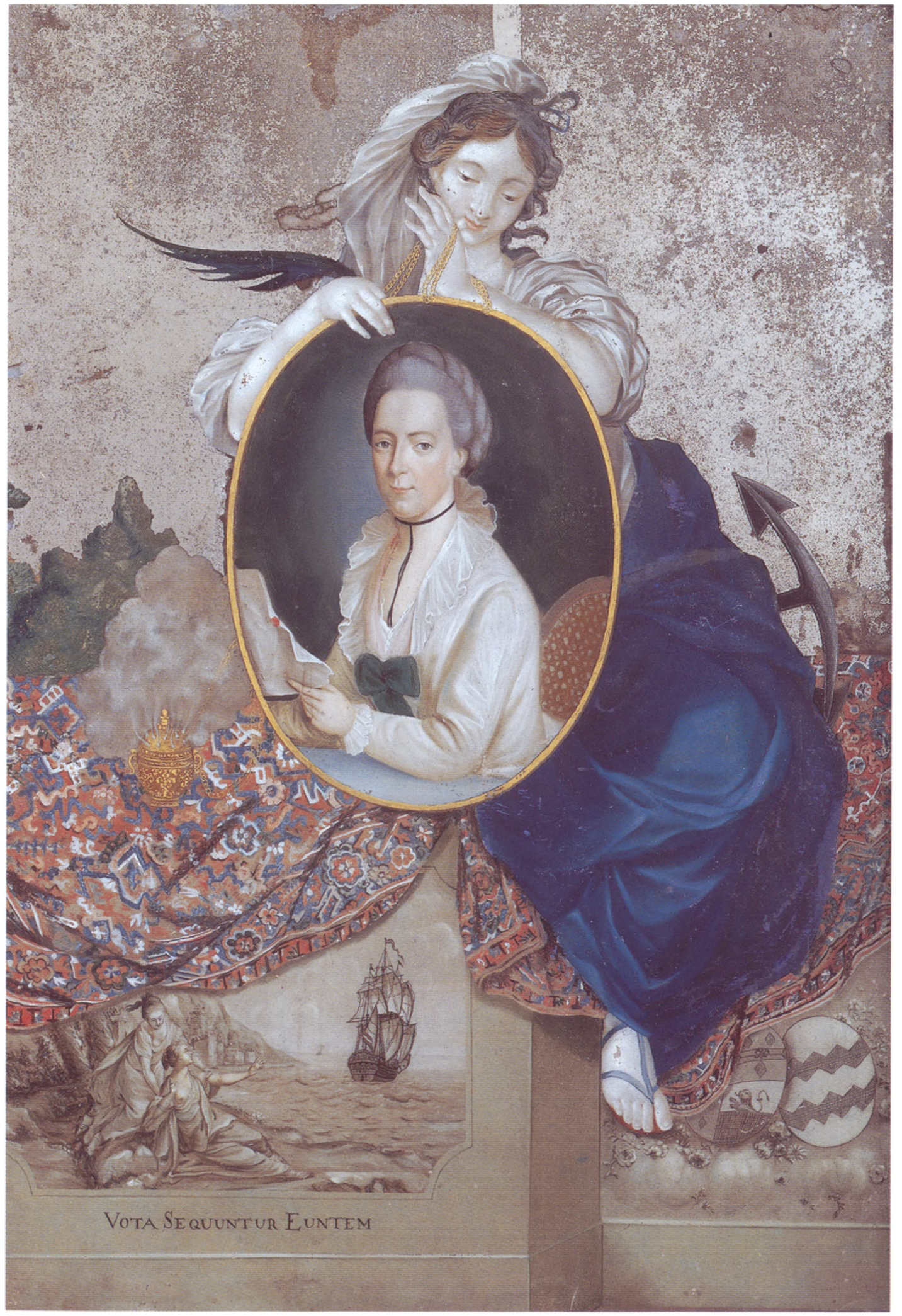




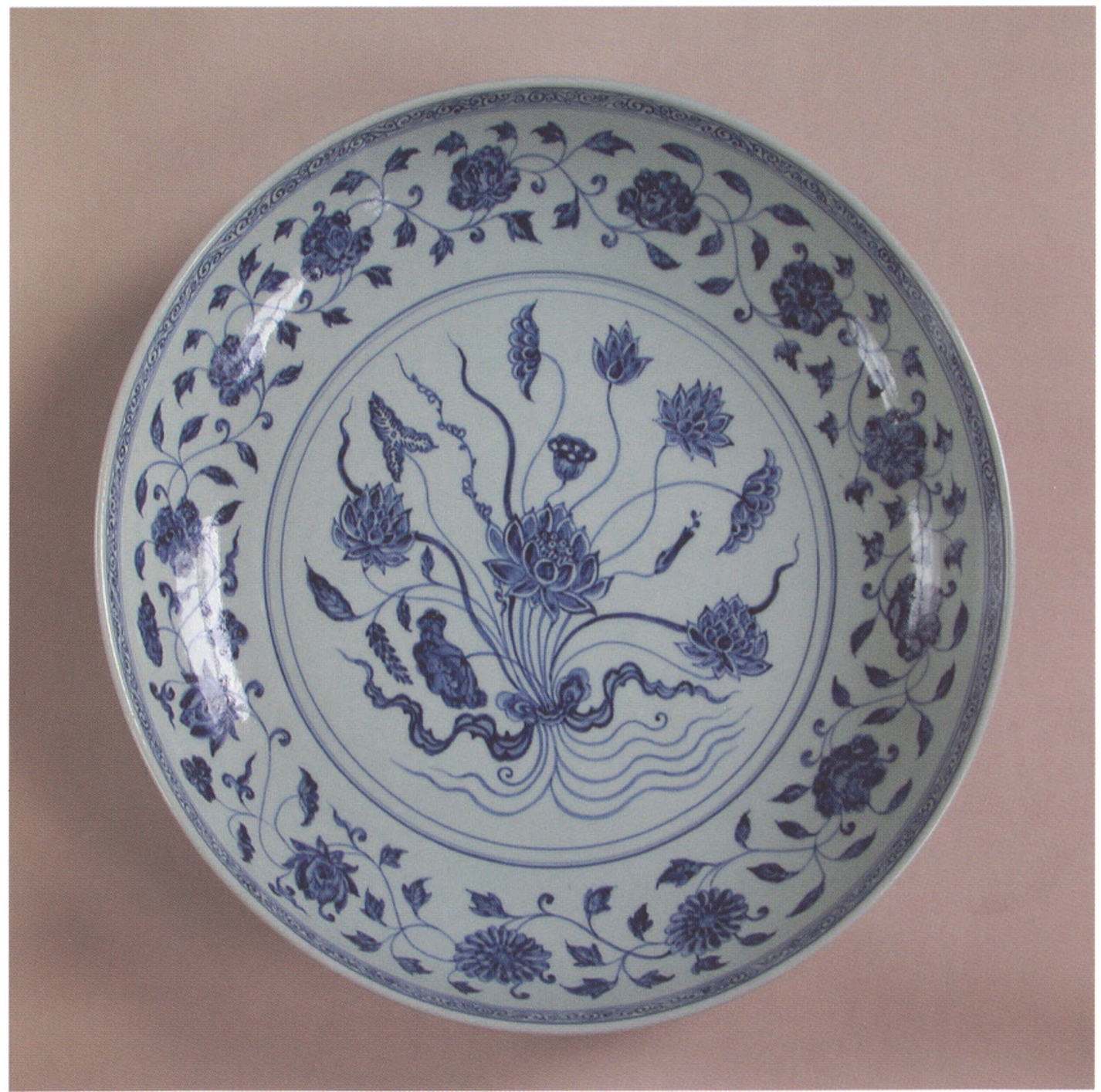

\section{Afbeelding 1}

Kopie van een

Chenghua bord,

vervaardigd door de

Maple hill-ovens te

Jingdezhen, China,

diam. $36 \mathrm{~cm}$. 